\title{
Role of lipid profile and uterine artery doppler in predicting risk of preeclampsia in early second trimester
}

\author{
Sheena Chopra*, Sangeeta Pahwa
}

Department of Obstetrics and Gynecology, Sri Guru Ram Das Institute of Medical Sciences and Research, Vallah, Amritsar, Punjab, India

Received: 23 March 2020

Accepted: 31 March 2020

*Correspondence:

Dr. Sheena Chopra,

E-mail: sheenachopra60@gmail.com

Copyright: () the author(s), publisher and licensee Medip Academy. This is an open-access article distributed under the terms of the Creative Commons Attribution Non-Commercial License, which permits unrestricted non-commercial use, distribution, and reproduction in any medium, provided the original work is properly cited.

\section{ABSTRACT}

Background: Preeclampsia is associated with adverse pregnancy outcome and is a major cause of the fetomaternal morbidity and mortality. This study aimed at finding the role of lipid profile and uterine artery Doppler as a reliable predictor of risk of preeclampsia in early second trimester.

Methods: This study is conducted in the obstetrics and gynecology department of a tertiary care teaching hospital, Amritsar. Lipid profile and Uterine artery doppler is estimated in 100 antenatal women from 14-20 weeks of period of gestation who met the inclusion criteria and are followed up till delivery or till preeclampsia sets in.

Results: Out of 100 subjects 74 remained normotensive (Group A) and 26 developed preeclampsia (Group B). The mean serum level of total cholesterol (TC), triglycerides (TG), low density lipoprotein cholesterol (LDL) and very low-density lipoprotein cholesterol (VLDL) was significantly higher in Group B as compared to group A women. The Preeclamptic women showed significant fall in high density lipoprotein cholesterol (HDL) level as compared to normal pregnant women. The mean S/D ratio, PI and RI values of uterine artery Doppler were higher for group B and were statistically significant.

Conclusions: The combined predictive value of lipid profile and uterine artery Doppler for estimating risk of preeclampsia was more reliable than of any of the test individually.

Keywords: Lipid profile, Preeclampsia, Uterine artery Doppler

\section{INTRODUCTION}

Hypertensive disorders complicate $5 \%$ to $10 \%$ of all pregnancies. Despite decades of extensive research, the exact mechanism as to how pregnancy initiates or aggravates the hypertension still remains unsolved. In India, the Incidence of preeclampsia is reported to be 8$10 \%$ among the pregnant women. ${ }^{1}$

Manifesting after 20 weeks of gestation in a previously normotensive women preeclampsia is a pregnancy specific multiorgan disorder characterized by systolic blood pressure $\geq 140 \mathrm{mmHg}$; diastolic blood pressure $\geq 90$
$\mathrm{mmHg}$ on at least two occasions at least 6 hours apart combined with proteinuria of $>300 \mathrm{mg}$ in 24 hours. $^{2}$

The primary cause of preeclampsia is abnormal placentation. Defective invasion of the spiral arteries by cytotrophoblast cells is observed during pre-eclampsia. The abnormalities may be related to the nitric oxide pathway, which contributes substantially to the control of vascular tone. Moreover, inhibition of maternal synthesis of nitric oxide prevents embryo implantation. Increased uterine arterial resistance induces higher sensitivity to vasoconstriction and thus chronic placental ischemia and oxidative stress. This chronic placental ischemia causes 
fetal complications, including intrauterine growth retardation and intrauterine death.

The most important feature in preeclampsia is vasospastic phenomenon in kidney, uterus, placenta and brain. Altered lipid synthesis causes decrease in PGI2:TXA2 ratio which is suggested to be an important pathway in pathogenesis in preeclampsia. ${ }^{3}$ Maternal serum lipids are significantly elevated during pregnancy. Women who develop preeclampsia experience even more dramatic lipid changes. Dyslipidaemia in early pregnancy leads to more oxidative stress by the formation of lipid peroxides and reactive oxygen species, thus predisposing to the development of pre-eclampsia.

During normal pregnancy, invasive cytotrophoblasts of fetal origin remodel maternal spiral arteries, causing them to dilate into large flaccid vessels. This remodelling process leads to an increase in flow in the fetomaternal circulation, which is required for adequate placental perfusion. Many studies have shown that increased impedance of blood flow in uterine arteries is associated with the development of PE and the results of previous first and second trimester Doppler studies are also compatible with histopathological findings of placentas from PE. The state of a high resistance of the uteroplacental circulation can be measured noninvasively by uterine artery Doppler ultrasound and help in predicting the risk of preeclampsia.

\section{METHODS}

The present study was conducted in the obstetrics and gynecology department of a tertiary care teaching hospital, Amritsar. After the approval of the institutional ethics committee and written informed consent from each antenatal woman, a total of 100 antenatal women with 14 -20 weeks of period of gestation were enrolled. The duration of my study was of 20 months (January 2018 to August 2019).

\section{For lipid profile}

Patients were called on a predetermined date corresponding with period of gestation of 14-20 weeks after overnight fasting and blood sample $(3 \mathrm{ml})$ was collected under all aseptic precautions for serum lipid profile in the biochemistry lab and tested on the same day. Estimation of lipid profile was done by the method of spectrophotometry. Lipid profile interpretation is done as per The National Cholesterol Education Program (NCEP) guidelines (units in $\mathrm{mg} / \mathrm{dl}$ ). ${ }^{4}$ VLDL cholesterol values in $\mathrm{mg} / \mathrm{dl}$ are indirectly measured.

\section{For uterine artery doppler}

At study institute VOLUSON E8 is used for the fetal well-being estimation and Doppler studies. Transabdominal uterine artery Doppler was done with curvilinear probe (1-5) by localizing the uterine artery at uterocervical junction where it appears to cross the external iliac artery. Peak systolic velocity was taken care of to be greater than $60 \mathrm{~cm} / \mathrm{s}$ to ensure that the arcuate artery is not being sampled instead of the uterine artery.

\section{The variables analyzed were}

- Resistance index (RI)

- Pulsatility index (PI)

- S/D ratio

- Early diastolic notch was watched.

Subsequent development of preeclampsia can be predicted when resistance index is more than 0.69 and pulsatility index is more than 1.4. The flow velocimetry waveform is considered abnormal if the S/D ratio is more than 2.6.

In spite of several studies having assessed the validity of uterine artery Doppler examination in first trimester to determine women at risk of developing early-onset preeclampsia, study conducted in early second trimester as most of the patients visit study hospital after the first trimester. Also, it is a well-established fact that the placentation implantation is complete by 14-18 weeks. Hence, the early second trimester was the best time for conducting this study.

\section{Inclusion criteria}

- $\quad$ Primigravida and multigravida with previous history of pregnancy induced hypertension

- $\quad$ Singleton pregnancy

- Approx. 14-20 weeks of gestation by first date of LMP (last menstrual period) or first USG.

\section{Exclusion criteria}

- Twin gestation

- Chronic hypertension

- Diabetes mellitus

- Preexisting heart/renal disease

- Trophoblastic disease

- Hypothyroidism.

Patients were followed up till delivery or till preeclampsia sets in, whichever is earlier. Mothers with previous history of PIH or those with dyslipidaemia and abnormal uterine artery Doppler were not provided any prophylaxis but they were closely monitored and provided strict maternal and fetal well-being assessment.

\section{Statistical analysis}

The continuous data were summarized as mean and standard deviation while discrete (categorical) in numbers and percentage $(\%)$. The continuous variables were compared by independent student's t test. The categorical variables were compared by chi-square $\left(\chi^{2}\right)$ test. The 
univariate and multivariate analysis were done with adjusted demographic variables. The $\mathrm{p}<0.05$ was considered statistically significant. All analysis was carried out using SPSS 20.0 version.

\section{RESULTS}

Out of the total 100 subjects 74 remained normotensive (Group A) till delivery of gestation and 26 of them (Group B) developed preeclampsia during the course of their pregnancy. The incidence of preeclampsia in this study is $26 \%$ as shown in the Table 1 .
Table 1: incidence of preeclampsia.

\begin{tabular}{|lll|}
\hline Groups & Incidence & Percent \\
\hline $\begin{array}{l}\text { Those who remained } \\
\text { normotensive (Group A) }\end{array}$ & 74 & $74 \%$ \\
\hline $\begin{array}{l}\text { Those who developed } \\
\text { preeclampsia (Group B) }\end{array}$ & 26 & $26 \%$ \\
\hline Total & 100 & $100 \%$ \\
\hline
\end{tabular}

The mean maternal age in the mothers who stayed normotensive was $25.8 \pm 3.48$ and in the mothers who became preeclamptic was $27.54 \pm 3.96(\mathrm{p}=0.227)$.

Table 2: Demographic profile of the subjects.

\begin{tabular}{|c|c|c|c|c|}
\hline & & Group A (74) & Group B (26) & p value \\
\hline Age & Mean \pm SD & $25.8 \pm 3.48$ & $27.54 \pm 3.96$ & 0.227 \\
\hline \multirow{2}{*}{ Parity } & Primigravida & $67(90.54 \%)$ & $15(57.69 \%)$ & \multirow{2}{*}{0.000} \\
\hline & Multigravida with previous history of PIH & $7(9.46 \%)$ & $11(42.31 \%)$ & \\
\hline \multirow{3}{*}{$\begin{array}{l}\text { Socioeconomic } \\
\text { status }\end{array}$} & Lower class & $10(13.51 \%)$ & $4(15.38 \%)$ & \multirow{3}{*}{0.487} \\
\hline & Middle class & $49(66.22 \%)$ & $14(53.85 \%)$ & \\
\hline & Upper class & $15(20.27 \%)$ & $8(30.77 \%)$ & \\
\hline \multirow{2}{*}{$\begin{array}{l}\text { Domiciliary } \\
\text { status }\end{array}$} & Rural & 53 & 14 & \multirow{2}{*}{0.097} \\
\hline & Urban & 21 & 12 & \\
\hline BMI & & $24.39 \pm 2.66$ & $25.30 \pm 2.58$ & 0.136 \\
\hline \multirow{2}{*}{ MAP } & At $14-20$ weeks & - & $90.15 \pm 7.41$ & 0.001 \\
\hline & At time of diagnosis & - & $113.13 \pm 4.64$ & 0.001 \\
\hline
\end{tabular}

In the 74 subjects of this study that remained normotensive $90.54 \%$ of them were Primiparous while only $9.46 \%$ of them were multigravida with previous history of PIH. While in the 26 subjects that developed preeclampsia $57.69 \%$ were primiparous and $42.31 \%$ were multigravida with previous history of PIH $(\mathrm{p}=0.000)$. Most of the cases in both groups belonged to middle class as categorised according to the socioeconomic status. This difference in both the groups was found statistically insignificant $(p=0.487)$. Most of the women in both groups of this study belonged to rural areas. 53 women from Group A and 14 from Group B were residing in rural area while 21 women from Group $\mathrm{A}$ and 12 from Group B were residing in urban area $(p=0.097)$. Maximum number of patients $(62.2 \%)$ in group A had normal BMI, $33.8 \%$ were overweight and $4.1 \%$ were obese. While in Group B $11.54 \%$ had normal BMI, $30.77 \%$ were overweight and $57.69 \%$ were obese. The mean BMI in Group A was found to be 24.39 \pm 2.66 while that in Group B was 25.30 \pm 2.58 . These values were found insignificant when statistically analysed $(p=0.136)$. Due to a smaller number of obese cases it is difficult to comment on the relation of preeclampsia risk in patients with $\mathrm{BMI}>30$. MAP was raised from $90.15 \pm 7.41 \mathrm{mmHg}$ at $14-20$ weeks to $115.13 \pm 4.64 \mathrm{mmHg}$ at the time of diagnosis $(\mathrm{p}=0.001)$ (Table 2). A total 9 cases of preeclampsia had the onset at gestational age between 28 -
32 weeks while 10 had the onset at gestational age after 32 weeks (Table 3 ).

Table 3: Distribution of cases according to the time of onset of preeclampsia.

\begin{tabular}{|l|l|}
\hline Gestational age & $\mathbf{n = 2 6}$ \\
\hline $20-24$ weeks & 3 \\
\hline $24-28$ weeks & 4 \\
\hline $28-32$ weeks & 9 \\
\hline $32-$ till delivery & 10 \\
\hline
\end{tabular}

The mean values of serum cholesterol, triglycerides, LDL and VLDL were more for preeclamptic group than the Normotensive one. This statistical difference is significant. Whereas mean values for serum HDL was more in the normotensive group. The odd's ratio and relative risk was calculated for the parameters of lipid profile for predicting preeclampsia and the values were found significant for all the parameters except for the HDL (Table 4). There exists a positive co-relation between serum cholesterol, triglycerides, LDL and VLDL with preeclampsia individually while there exists negative co-relation between HDL and preeclampsia. Thus, the linear regression was obtained on the scatter diagrams which establishes the fact that the lipid profile could statistically significantly predict the risk of developing preeclampsia in this study (Table 5). 
Table 4: Findings of lipid profile in this study.

\begin{tabular}{|llllll|}
\hline Lipid profile & Group A $(\mathbf{n}=\mathbf{7 4})$ & Group B $(\mathbf{n = 2 6})$ & Odds ratio & Relative risk & Significance \\
\hline & Mean \pm SD & Mean \pm SD & & & \\
\hline Cholesterol & $210.22 \pm 52.39$ & $256.23 \pm 70.96$ & 4.8022 & 3.3175 & 0.0023 \\
\hline Triglycerides & $146.93 \pm 47.49$ & $211.06 \pm 87.99$ & 5.1136 & 3.3750 & 0.0011 \\
\hline HDL & $58.31 \pm 15.35$ & $45.52 \pm 12.31$ & 2.2933 & 1.8783 & 0.0714 \\
\hline LDL & $119.11 \pm 46$ & $139.97 \pm 40.45$ & 4.3622 & 3.0608 & 0.0045 \\
\hline VLDL & $33.63 \pm 11.37$ & $47.62 \pm 27.55$ & 4.0833 & 2.7222 & 0.0022 \\
\hline
\end{tabular}

Table 5: Regression analysis and predictive outcome of lipid profile.

\begin{tabular}{|llllll|}
\hline & Cholesterol & Triglycerides & HDL & LDL & VLDL \\
\hline R value & 0.333 & 0.425 & 0.361 & 0.203 & 0.342 \\
\hline Degree of freedom & 1 & 1 & 1 & 1 & 1 \\
\hline Significance & 0.001 & 0.000 & 0.000 & 0.043 & 0.000 \\
\hline Sensitivity & $76.19 \%$ & $76.19 \%$ & $19.05 \%$ & $76.19 \%$ & $61.90 \%$ \\
\hline Specificity & $63.29 \%$ & $69.62 \%$ & $59.49 \%$ & $60.76 \%$ & $78.48 \%$ \\
\hline PPV & $35.56 \%$ & $40.00 \%$ & $11.11 \%$ & $34.04 \%$ & $43.33 \%$ \\
\hline NPV & $90.91 \%$ & $91.67 \%$ & $73.44 \%$ & $90.57 \%$ & $88.57 \%$ \\
\hline Accuracy & $66.00 \%$ & $71.00 \%$ & $51.00 \%$ & $64.00 \%$ & $75.00 \%$ \\
\hline
\end{tabular}

Table 6: Findings of uterine artery doppler.

\begin{tabular}{|c|c|c|c|c|c|}
\hline \multirow[b]{3}{*}{$(\mathrm{MEAN} \pm \mathrm{S} . \mathrm{D})$} & & S/D ratio & PI & RI & DN \\
\hline & Group A & $2.2456 \pm 0.6689$ & $0.9484 \pm 0.4252$ & $0.55 \pm 0.174$ & \\
\hline & Group B & $3.09 \pm 1.41$ & $1.44 \pm 0.56$ & $0.68 \pm 0.13$ & \\
\hline Odds ratio & & 6.6286 & 6.4697 & 8.8727 & 7.0714 \\
\hline Relative risk & & 3.7333 & 3.5000 & 4.3259 & 3.4286 \\
\hline Significance & & 0.0001 & 0.0001 & 0.0001 & 0.0001 \\
\hline Sensitivity & & $66.67 \%$ & $57.14 \%$ & $66.67 \%$ & $42.86 \%$ \\
\hline Specificity & & $79.75 \%$ & $83.54 \%$ & $83.54 \%$ & $98.73 \%$ \\
\hline PPV & & $46.67 \%$ & $48 \%$ & $51.85 \%$ & $90.00 \%$ \\
\hline NPV & & $90.00 \%$ & $88.00 \%$ & $90.41 \%$ & $86.67 \%$ \\
\hline Accuracy & & $77.00 \%$ & $78.00 \%$ & $80.00 \%$ & $87.00 \%$ \\
\hline
\end{tabular}

The mean values of S/D ratio, PI and RI are higher in the group that developed preeclampsia than the group that remained normotensive. The odd's ratio and relative risk for predicting preeclampsia of the uterine artery Doppler parameters is found statistically significant in this study group. As can be seen S/D ratio has a better Sensitivity (66.67\%), specificity $(79.75 \%)$ and negative predictive value $(90 \%)$ in predicting preeclampsia. PI $(83.54 \%$, $88 \%)$, RI $(83.54 \%, 90.41 \%)$ and diastolic notch $(98.73 \%$, $86.67 \%$ ) has a good specificity and negative predictive value for preeclampsia but a rather poor sensitivity for the same. Diastolic notch has a good positive predictive value (90\%) as well (Table 6).

The combined sensitivity for both lipid profile and uterine artery Doppler was found to be $75 \%$ and the specificity as $91.97 \%$. The PPV and NPV was found to be $75 \%$ and $91.67 \%$ respectively. Hence the combination of the tests has better predictive value than either of the test used alone (Table 7).
Table 7: The combined predictive values for lipid profile and uterine artery Doppler.

\begin{tabular}{|ll|}
\hline Lipid profile & Values \\
\hline Sensitivity & $75.00 \%$ \\
\hline Specificity & $91.67 \%$ \\
\hline PPV & $75.00 \%$ \\
\hline NPV & $91.67 \%$ \\
\hline Accuracy & $87.50 \%$ \\
\hline
\end{tabular}

Table 8: Pregnancy outcome in Group B subjects.

\begin{tabular}{|lll|}
\hline Complications & $\mathbf{n = 2 6}$ & \% \\
\hline Mild preeclampsia & 12 & $46.15 \%$ \\
\hline Severe preeclampsia & 1 & $3.85 \%$ \\
\hline Eclampsia + IUD & 2 & $7.69 \%$ \\
\hline IUGR & 8 & $30.77 \%$ \\
\hline IUD & 3 & $11.54 \%$ \\
\hline
\end{tabular}


In this study of 100 subjects, 74 remained normotensive after 20 weeks of gestation while 26 developed preeclampsia. Out of these 26 preeclamptic - $12(46.15 \%)$ subjects had mild preeclampsia, 1(3.85\%) developed severe preeclampsia, 2 (7.69\%) had eclampsia with IUD, 8 had IUGR and remaining 3 subjects had only IUD (Table 8).

\section{DISCUSSION}

The hypertensive disorders may manifest later in pregnancy but the underlying mechanisms start operating much early in pregnancy. Thus, with this background researchers are trying to look for early markers so that early diagnosis and timely management can be provided to the high-risk patients.

Most patients who will develop pre-eclampsia can be identified either by epidemiological, biophysical or biochemical markers. However, wide physiological variability of these markers leads to high false-positive predictions. The timing of testing is critical to the disease being predicted. First trimester screening is unlikely to give useful predictions of term onset pre-eclampsia, but can achieve excellent results for the more serious forms that require preterm delivery. Late onset disease can be predicted more accurately by second trimester measurements.

Through this study aim to identify the predictability of a biochemical and biophysical markers - lipid profile and uterine artery Doppler in 14-20 weeks of gestation for preeclampsia. Both these tests are easily affordable, noninvasive and thus the choice for the study.

Mean age of Group A in this study was $25.8 \pm 3.48$ years. and that in Group B was 27.54 \pm 3.96 years. This difference in age group on analysis was not found significant in this study $(\mathrm{p}=0.227)$. Thus, the two groups were comparable in terms of age as demographic factor. Kumari K et al found that proportion of higher age group was significantly higher in study group as compared to control group. ${ }^{5}$ Similar to the present study, Padmapriya et al, conducted a study of "lipid profile in second trimester of pregnancy as a predictor of preeclampsia in patients attending antenatal clinic in Kilpauk medical college and hospital". 6 They also did not find any statistical significance with respect to age distribution in both the groups.

In this study we recruited primigravida's or multigravidas with previous history of PIH disorder aged 19-36 years. In this study, among the preeclamptic group, $57.69 \%$ are primigravidae and $42.31 \%$ are multigravida with previous history of PIH. Out of the 82 primigravida's, 15 (18.29\%) developed preeclampsia while out of the 18 multigravidas with previous history of preeclampsia 11 (61.11\%) developed preeclampsia. This comparison in terms of parity was found statistically significant $(\mathrm{p}=0.000)$.
Kooffreh ME et al in their study on the prevalence of preeclampsia among pregnant women including 8524, showed that majority of the patients between the age group of 25-29 years that is about 104 patients were primigravida but none of their subject in multigravidas had previous history of PIH. ${ }^{7}$ In this study found, mothers with previous history of PIH are at a higher risk of recurrence in the next pregnancy as well.

Sensitivity, specificity and NPV was higher for serum cholesterol $(76.19 \%, 63.29 \%, 90.91 \%)$, triglycerides $(76.19 \%, 69.62 \%, 91.67 \%)$ and LDL $(76.19 \%, 60.76 \%$, $90.57 \%)$. VLDL had a relative lower sensitivity $(61.90 \%)$ yet higher specificity $(78.48 \%)$ and a good NPV $(88.57 \%)$. HDL on the other hand had a poor sensitivity (19.05\%), specificity $(59.49 \%)$, PPV $(11.11 \%)$ but a relative good NPV $(73.44 \%)$.

The relationship between abnormal lipid profile and hypertension has been studied by a number of investigators with some studies showing association of some of the parameters of lipid profile and others showing association of all the parameters with hypertension. In the studies of Mukherjee et al8 and Gohil et al, the serum TG, TC, LDL and VLDL levels were significantly higher and HDL significantly lower in preeclamptic women compared to normotensive pregnant women. ${ }^{9}$ Vidyabati et al concluded that total cholesterol; VLDL, and LDL in women who subsequently developed PIH were significantly higher than in normotensive patients. ${ }^{10}$

Vani I et al in their clinical study to compare the lipid profile in normotensive and hypertensive pregnant women found a significant increase $(p<0.5)$ in total cholesterol, LDL cholesterol, VLDL cholesterol and triglycerides in preeclamptic group compared to normotensive group. ${ }^{11}$ There was a significant decrease in HDL cholesterol in preeclamptic group. This study in correlation with various other studies concluded that dyslipidemia plays an important role in the pathogenesis of preeclampsia.

The sensitivity, specificity and NPV in this study was higher for S.D ratio $(66.67 \%, 79.75 \%$, and $90.00 \%)$ and RI $(66.67 \%, 83.54 \%$, and $90.41 \%)$. PI $(57.14 \%, 83.54 \%$, and $88.00 \%)$ and diastolic notch $(42.86 \%, 98.73 \%$, $86.67 \%$ ) has lower sensitivity and rather higher specificity and NPV.

Rupnawar $\mathrm{P}$ et al conducted a prospective observational study to assess Uterine Artery Doppler findings at 18-22 weeks of gestation in 140 women. ${ }^{12}$ Out of 28 women with abnormal doppler findings 8 developed preeclampsia. The sensitivity of SD ratio was found to be $62 \%$, for RI $50 \%$ and for diastolic notch $62.5 \%$.

Our results were comparable with the study by Sahoo et al who found increased RI (Resistance Index) and PI (pulsatility index) than their normal values in majority of 
preeclamptic patients during the gestation of 14-20 weeks. ${ }^{13}$

We wanted to study the combined predictability of both biochemical and biophysical test for preeclampsia thus, we studied their collaborative outcome. The Sensitivity was found to be $75 \%$, specificity as $91.67 \%$, PPV as $75 \%$, NPV as $91.67 \%$ and accuracy as $87.50 \%$ for the combination profile of lipid profile and uterine artery Doppler.

Study found that when both the tests were found normal, $44(59.5 \%)$ of subjects were normotensive and only 4 subjects $(15.4 \%)$ developed preeclampsia. But when both the tests had raised values, only $4(5.4 \%)$ remained normotensive while 12 subjects (46.2\%) had preeclampsia. Thus, combining both the tests can help in better predictability of the development of preeclampsia than using the either of the tests individually.

The pregnancy outcomes in study subjects of group B showed a lot of variance. Out the total 26 subjects, 12 remained only mild preeclamptic, $1(3.85 \%)$ developed severe preeclampsia, $2(7.69 \%)$ developed eclampsia and had IUD of the fetus, $8(30.77 \%)$ developed IUGR along with and $3(11.54 \%)$ had IUD of the fetus due to preeclampsia.

More and more prospective clinical trials are required to establish the clinical utility of biomarkers or their combination with biophysical variables that will help determine ways to differentiate women destined to develop preeclampsia from those who will not.

The strength of this study lies in the fact that while there are several studies that showed the relationship between increased BMI and increased risk of preeclampsia but this study has no such co-relation and hence the confounding bias with respect to BMI is not present in this study.

The limitation of this study is that the study population belonged majorly to rural area and the middle class. Hence the results cannot be generalized to a larger population. Also, a single measurement of blood samples may have resulted in some misclassification of maternal lipid profiles during pregnancy so, longitudinal studies with serial measurements of maternal lipid concentrations are needed for a better co-relation with preeclampsia.

\section{CONCLUSION}

Thus, both lipid profile and uterine artery Doppler are reliable predictors of preeclampsia as can be inferenced from this study. Both the tests are feasible, easily available and are cheaper than most of the other biomarkers. More and more research is needed and also studies on large scale are required to establish the role of lipid profile with uterine artery Doppler in early second trimester as predictors of preeclampsia.

Funding: No funding sources

Conflict of interest: None declared

Ethical approval: The study was approved by the Institutional Ethics Committee

\section{REFERENCES}

1. Cunningham F, Leveno KJ, Bloom SL, Hauth JC, Rouse DJ, Spong CY. Pregnancy hypertension: Text book of Williams Obstetrics; 2005;23(36):706-49.

2. Ghulmiyyah L, Sibai B. Maternal mortality from preeclampsia/eclampsia. Seminars Perinatol. 2012;36(1):56-9.

3. Shanmugavadivu L, Sundari K, Devi P. Early predictors of PIH: serum beta-HCG and lipid profile. Inter J Reprod Contracept Obstet Gynecol. 2016;4142-5.

4. Expert Panel on Detection E. Executive summary of the third report of the National Cholesterol Education Program (NCEP) expert panel on detection, evaluation, and treatment of high blood cholesterol in adults (Adult Treatment Panel III). JAMA. 2001;285(19):2486.

5. Kumari K, Singh U, Maharshi S, Singh R. Assessment of serum lipid profile in early pregnancy and its relation with pre-eclampsia: a prospective study. Int J Reprod Contracept Obstet Gynecol. 2016;5:840-4.

6. Padmapriya M. Padmapriya M. Lipid profile in second trimester of pregnancy as a predictor of preeclampsia in patients attending antenatal clinic in Kilpauk Medical College and Hospital: A prospective cohort study (Doctoral dissertation, Kilpauk Medical College, Chennai). 2013. Available at: repository-tnmgrmu.ac.in/8528/. Accessed on $15^{\text {th }}$ May 2019.

7. Kooffreh M, Ekott M, Ekpoudom D. The prevalence of pre-eclampsia among pregnant women in the University of Calabar Teaching Hospital, Calabar. Saudi J Health Sci. 2014;3(3):133.

8. Mukherjee R, Ray CD, Chakraborty C, Dasgupta S, Chaudhury K. Clinical biomarker for predicting preeclampsia in women with abnormal lipid profile: statistical pattern classification approach. Inter Conf Syst Med Biol. 2010:397-401

9. Gohil J, Patel P, Gupta P. Estimation of lipid profile in subjects of preeclampsia. The J Obstet Gynecol India. 2011;61(4):399-403.

10. Vidyabati R, Hijam D, Singh N, Singh W. Serum ßhCG and lipid profile in early second trimester as predictors of pregnancy induced hypertension. The $\mathbf{J}$ Obstet Gynecol India. 2010;60(1):44-50.

11. Vani I, Gayathri A, Nagamani T, Sunieeta H. Lipid profile parameters in normal and preeclampsia complicating pregnancies-a prospective observational study. The Am J Sci Med Res. 2015;1:40-3. 
12. Rupnawar PB, Ajith S, Rajalakshmi TN. To assess uterine artery Doppler findings at 18- 22 weeks in predicting adverse pregnancy outcome. IOSR 2015;14(8):95-100.

13. Sahoo K, Shaha P, Bhairagond S, Raj V. The Role of Uterine Artery Doppler Sonography in Predicting Pre Eclampsia at 14-20 Weeks of Gestation. Inter J Sci Res (IJSR). 2016;5(2):37-47.
Cite this article as: Chopra S, Pahwa S. Role of lipid profile and uterine artery doppler in predicting risk of preeclampsia in early second trimester. Int J Reprod Contracept Obstet Gynecol 2020;9:1806-12. 